\title{
Development Pattern of Traditional Chinese Arts and Crafts under the Reform and Opening up Policy (1988 1998)
}

\author{
Jinling $\mathrm{Li}^{1}$ \\ Yantai Nanshan College \\ Yantai Longkou, Shandong, China \\ e-mail: sohell@163.com
}

\author{
Shuangqing $\mathrm{Hou}^{2}$ \\ Yantai Nanshan College \\ Yantai Longkou, Shandong, China \\ e-mail: weishui1985@163.com
}

\begin{abstract}
Chinese traditional arts and crafts act as the unique carrier of the material, spirit and system culture in the process of creation history. It has distinctive brand of the times in the heritage, evolvement, transition and innovation. From 1988 to 1998, it is a period of adjustment and integration of Chinese cultural industrial policy and various cultural thoughts. Traditional Chinese arts and crafts have faced both opportunities and challenges in the industry pattern, discipline pattern and education pattern, and have strived to make innovations.
\end{abstract}

Keywords-industrial policy; traditional arts and craft; industrial pattern

\section{INTRODUCTION}

From 1798 to 1988 , it is an initial period of the implementation of the policy on the national cultural industry since the reform and opening up policy. From 1988 to 1998 (The year 1998 is a time node. The period after 1998 is the period for overall promotion and adjustment of China's accession to the WTO and the cultural industry. In August 1998, the Cultural Department of the Ministry of Culture was established and has formulated its work rules. It is the first time for the governmental organization to establish a department specialized in the management of the cultural industry.), it is the period of development and maturity for the market economy. The government implemented the policy of promoting a variety of schools and thoughts and the stable cultural policy, which provides an opportunity for the development of the traditional arts and crafts. At the same time, the traditional arts and crafts have got rid of their perplexing historical positions, but its new development path needs to be perfected. In addition to the booming of the industrial pattern and discipline education, the collision and connection between the concept of "art design" and the arts and crafts have become the focus of academic attention.

II. CONCEPT EVOLUTION: THE TRADITIONAL ARTS AND CRAFTS BETWEEN “ART AND CRAFT" AND "ART DESIGN"

By the 1980s, the traditional arts and crafts have developed into an art pattern with handicraft as the main operating skill. It has two main characteristics-inheritance and technology. The traditional arts and crafts in general sense refer to the traditional products with certain of artistry and strong manual skills, which were mainly formed in the stage of the handicraft industry. And the arts and crafts are creatively featured by the combination of utilization and beauty, such as the well-known ceramic, jade carving, ivory carving, cloisonné, lacquer carving, wood carving, shadow puppet, kite, colored lanterns, paper cutting, mud figure, embroidery, drawn work and so on1. From the reference of "pattern theory" originated in Japan to the concept of "arts and crafts" clearly put forward by the Educator Mr. Cai Yuanpei in the 1920s (May 1920), the concept of "arts and crafts" has been used till 1980s. After this, both the two concepts of "arts and crafts" and "design" began to be used in the academic circles. In fact, these two concepts are not opposite. However, their disciplines and contents are different. In order to distinguish them, "industrial art design", "art design" and "design" and some other concepts rose at the historical moment. ${ }^{2}$

\section{THE PROMOTION OF THE LEGITIMATE}

FORMULATION OF THE CULTURAL INDUSTRY POLICY ON THE CONSTANT-SPEED DEVELOPMENT OF THE TRADITIONAL

\section{ARTS AND CRAFTS}

Since the beginning of 1990s, peaceful development and common prosperity have become the world's consensus. It is encouraged that we should respect cultures of different nations and regions and we should also respect the any paths of development around the world that is different for ours. The culture integration has become a new topic.

\section{A. The role of cultural policies of Europe, America, Japan and South Korea in promoting cultural industries}

1) Cultural policies earlier implemented in European and American countries: As early as in 1793, when many countries did not realize the cultural heritage protection, France had already enacted the "Decree for the First Year of Republican", mandating the protection for all classes of artworks throughout the territory of France, and it also involved the handicraft workshop for the purpose of teaching the craftsmanship. Commonwealth countries and EU countries introduced the

\footnotetext{
${ }^{1}$ Li Yanzu. Material and Non-material: Protection and Development of Traditional Arts and Crafts [J]. Literature and Art Study, 2006 (12): 106-117.

2 Yu Qiang. Introduction to Design Art [M]. Chongqing: Chongqing University Press, 2006:11.
} 
"originality-themed" cultural policies respectively in 1993 and 1998, which evoked repercussions in Chinese cultural and academic circles, and a series of research results were made focus on "high-tech and high culture", knowledge-based economy and cultural industries (or "content industries" or "creative industries"). The tough negotiation on China's accession to the WTO at the turn of the century enhanced the above impact. Although the GATS do not involves the cultural trade service too much, people can still sense that the international cultural competition is extremely fierce.

2) The direct impact of Japan's strategy of protection for traditional arts and crafts: In May of 1871 (the fourth year of Meiji period), Japanese government enacted the "Plan for the Preservation of Ancient Artifacts" aimed at protecting arts and handicrafts, which is the first law for the protection of cultural heritage that Japanese government issued in the form of decree. In 1974, Japanese government formulated and implemented the "Law of Promoting the Industry of Traditional Arts and Crafts", which is a law developed specially for the further promotion of traditional handicrafts. Combined with the survey of arts and crafts industry, it established a nationwide professional association covering cities, towns and villages, and the involvement of state and local government improved people's awareness of protection and trained talents in the field of protection for cultural property.

3) South Korea: Science and technology boosted the appreciation of traditional arts and crafts : After the economic crisis in 1998, the South Korea decisively proposed the policy of "culture-nurtured country" to develop the cultural industries into the strategic pillar industry of national economy in the $21 \mathrm{st}$ century. Later, the South Korea stipulated the development of cultural industries as the statutory function of government, set up perfect cultural management mechanism, and established the Korea Creative Content Agency from central to the local. The main characteristic of Korean traditional arts and crafts is to place emphasis on the science and technology, and integrating the modern technology, material and design concepts into the Korean traditional arts and crafts, which is the mark of the Korean modern arts and crafts. It changes the employment structure, management and innovative concept of arts and crafts personnel in consequence. What we can learn from it is to promote the traditional arts and crafts industry into the hi-tech enterprise and to attach great importance to the introduction of modern science and technology in the traditional arts and crafts so as to realize the transmission and promotion of traditional arts and crafts.

\section{B. Chinese Traditional Arts and Crafts under the Policy of Cultural Industries}

1) Reasonable construction of the policy of cultural industries: At the same period, Chinese arts and crafts obtained its new development owing to the reasonable construction of cultural industries, and the comprehensive advance of cultural market also provided empirical guidance for the cultural economy. The concept of "arts and crafts" which has been used in history is being replaced gradually by the concept of "arts and design" or the "design", and it is typical that the laws and regulations for the development of arts and crafts were issued for the first time in our country, namely, "Regulations on Protection of Traditional Arts and Crafts" of 1997, which has a profound effect on the protection and development of traditional arts and crafts.

In 1988, the Ministry of Culture and the State Administration for Industry and Commerce jointly issued the "Notification on Further Enhancing the Management of Cultural Market". As a milestone document, it proposed the concept of "cultural market", specifying the management scope, tasks, principles and guidelines and marking that the status of Chinese "cultural market" was officially recognized. In 1989, the State Council approved the Ministry of Culture for the establishment of Cultural Market Authority, and the national cultural market management system was set up. In 1991, the "Report of Several Opinions on the Economic Policies of Cultural Undertakings by the Ministry of Culture" was approved by the State Council, which thereafter officially proposed the concept of "cultural economic". In August of 1998, the Division of Cultural Industries of the Ministry of Culture was established for the first time as a special cultural industry management authority and the working rules were formulated, marking that the government confirmed the legitimacy of the cultural industry and will have an increasing emphasis on it after that.

Under the influence of a series of policies, public-owned enterprises continued to accelerate the pace of reform. The arts and crafts enterprises began their restructuring and transformation. Confronted with increasingly fierce market competition, most of the manual production-oriented arts and crafts enterprises, especially the state-owned and collectivelyowned enterprises, were unsustainable, among which some were transformed into private enterprises or went bankrupt. During the five-year plan from 1995 to 1999, China has implemented the policy of developing the country through science and education. The Beijing Industrial Design Center, established in 1995 and affiliated with Beijing Municipal Science and Technology Commission, was an institution committed to building a platform for specialized technology sharing of design ideas, information, materials, models, testing and so on. It recognized that design must make new progress. In the process of industrial development, China has increased a lot of design and education curriculum and attracted a great number of students, and the arts and crafts industries begun to explore in practicing new ways to link the markets at home and abroad.

2) The industrial pattern of domestic sales of commodities originally produced for export: The early 80s saw an output value of over 5 billion Yuan with the domestic sales appropriately accounting for one-fifth of the total proportion and the production was mainly oriented to the export. For example, at two important bases for the production of traditional arts and crafts in Beijing and Shanghai, there were 60 professional manufacturers, including 12 commercial enterprises and joint ventures. Products were exported to more than 100 countries and regions and the traditional handicraft became a hit product to increase the foreign exchange earnings. 
Since mid-1990s, the traditional arts and crafts experienced its new stage of development. On the one hand, due to the growth in domestic demand and export competition, domestic sales became a new drive for the economy; on the other hand, with the reform of production system, most of the arts and crafts enterprises were transformed, creating a new pattern of production of arts and crafts since the foundation of new China. In the overall industrial pattern, many industry-oriented cities emerged, and arts and crafts in different regions mostly became the backbone of local traditional industry or symbols of cities: such as Jingdezhen ceramics, Yixing clay teapots, Nanjing brocade, Suzhou embroidery, Fuzhou bodiless lacquer ware, Beijing cloisonné and so on.

3) Regulations on the Protection of Traditional Arts and Crafts: Although the economic and technical integration and cultural globalization have created opportunities for the Chinese traditional arts and crafts industries, it also caused difficulties in the protection of traditional tangible and intangible cultural heritages. The power of technology, capital and culture acted like an invisible hand to promote the cultural changes in the Chinese society. In response to the loss of traditional cultural trait caused by the above changes, the State Council issued in 1997 the "Regulations on Protection of Traditional Arts and Crafts". The "Regulations on Protection of Traditional Arts and Crafts", which was issued on May 20, 1997 (promulgated by Decree No. 217 of the State Council of the People's Republic of China), is a major measure to protect the traditional arts and crafts in the form of regulations and in the name of the state for the first time in the Chinese history. It is also a law requiring the creation of facilities for masters of arts and handicrafts to take on apprentices and pass on the techniques; 3 taking on apprentices and passing on the techniques is not only the core concept of transmission and development of traditional arts and crafts, but also the key factor in achieving the effective transmission of tradition arts and crafts. The "Regulations on Protection of Traditional Arts and Crafts" aimed at the establishment of the base for protecting traditional arts and crafts; the collection and storing up of excellent representative works; organizing masters of arts and handicrafts to create excellent works; training talent of traditional arts and crafts; 4Since then, Beijing, Shanghai, Jiangsu, Guangdong, Hebei, Zhejiang, Anhui, Sichuan, Chongqing and other provinces and cities formulated or enacted appropriate regulations or measures on protection for local arts and crafts, and a batch of new private or individual enterprises grew up gradually and became the main body of industry. Apart from this, many provinces and cities in our country also formulated protection regulations and specific rules for implementation according to the actual conditions.

\footnotetext{
${ }^{3}$ State Council (General Office of the State Council), Regulations for the Protection of Traditional Arts and Crafts, Decree of the State Council No. 217 [1997-05-20]. Cultural Policy Libraryhttp://www.cpll.cn/law298.shtml ${ }^{4}$ Ditto 3
}

\section{THE TRADITIONAL ARTS AND CRAFTS UNDER THE VIEW OF "ART DESIGN"}

With the deepening of reform and opening up policy, the society, the politics and the economy have progressed steadily. A variety of western design thoughts, methods and ideas were brought into China. The receiving and using of design experience, method and category are the most significant impacts on the spread of the idea of "art design". The concept of "arts and crafts" is still being used at home. Through the theoretical analysis of previous educational circles, the development and perfection of arts and crafts and the spread of art design, the Ministry of Education has made an adjustment on the discipline catalog in 1998. Since then, "art design" or "design" replaced the "arts and crafts". It is subject to machine production, but the traditional arts and crafts didn't decline. However, the mechanical skills are also used in the production process and displayed through the manufacturing quality, so the machine skills could be and should be included in the technology scope. It may not be the opposite of handicraft skill. 5In the aspect of profession and market linkage, the traditional arts and crafts take inheritance and innovation as the property.

\section{A. The discipline education of arts and crafts}

From 1950s to the early 1980s, the teaching direction of arts and crafts began to be divided. On the one hand, it develops into a variety of professions such as art, decoration and design. With the deepening of reform and opening up policy and the abundance of material life especially in the late 1980 s, the arts and crafts has constantly experienced the innovation on the discipline construction with the development of industrial pattern. Most colleges, universities, fine arts colleges and departments have adjusted their professional directions. Other comprehensive universities and engineering colleges have also set up the industrial design, decoration design, dying and weaving design, advertising design, decoration art design and other disciplines, which complemented each other with the growing market economy. Since the 1990s, the high education has developed rapidly. Some comprehensive universities, science and engineering universities and arts colleges began to set up specialties related to art design. Meanwhile, some single-discipline colleges have also opened "new specialties" and introduced "professionals". The dominant pattern of disciplines and specialty direction, teachers and teaching was broken apart, and art education has been developed in a large scale. In 1986, the fourth report of the 6th National People's Congress has re-declared the importance of the aesthetic education, which has pushed the development of art education in the 1980s and 1990s.

\section{B. The problems of talent training of traditional arts and crafts}

Aiming at solving the problems in the discipline and profession and professional direction setting, a survey was made upon the teaching and market linkage. It showed that the

5 Tony Fretton. Divine Design - Recreation Theory [M]. See: Design Discovery - Research and Study of Design | Collection of Translation on Design History and Material Culture. (the United States) Ed. Richard Buchanan \& Victor Margolin; Translator: Zhou Dandan \& Liu Cun; Editor: Yuan Xiyang \& Gu Huaming. Nanjing: Jiangsu Fine Arts Publishing House, 2010: 204. 
problems of talent training were increasing day by day. Due to the talent training foundation of the past 30 years (for earning foreign exchange through exports after the founding of the PRC), it was the golden period for the development of the traditional arts and crafts. From the beginning of 1950s, most of the arts and crafts enterprises were under collective ownership. Only less than $10 \%$ are state-owned enterprises. These enterprises under the leadership of local arts and crafts head office or the department of light industry, trained talents with modern skills almost all over from the beginning. For example, they opened arts and crafts vocational secondary schools, set up administrative office in the factory or ordering the relevant enterprise to open corporate occupational schools. The National Central Academy of Fine Arts founded in 1956 also shouldered the task to cultivate the talents. Meanwhile, the arts and crafts factories and enterprises generally invited the master workers to train less-skilled workers, training a large group of arts and crafts technicians. The technical force has made a great contribution to the development of arts and crafts industry since the 1980s. However, after the transition of the economic system in the 1990s, the individual and private enterprises become the main body of the traditional arts and crafts industry. These enterprises simply focus on the production and operation. The talent training relies on a single mode of the traditional way by training skilled personnel, and the quantity and quality have been unable to meet the needs of the industry and the development of cultural undertakings. The shortage of relevant talents has begun to restrict the development of the industry. What are worse, the national, planning and long-term talent training and the initiative of all levels to develop education have now been greatly reduced. The previous arts and crafts technical schools and colleges mostly do not engage in student enrollment and education in the traditional arts and crafts due to various reasons, which results in the lack of an important ring on the talent training of the traditional arts and crafts. If such situation lasts for long, the result will be more serious. It is the time for the country to take into consideration and solve the problems on the education development and talent training in this area. In addition, the craft artists trained in the 1950s are overconfident in their profession and lack the necessary consciousness of sharing their skills. To be punctual and available become the technological fate of this generation.

\section{CONCLUSION}

In the 1980s, the transition, spread and influence of various western thoughts have brought new challenges to our society in the reformatory and flourishing period. The traditional arts and crafts have reflected that the path of development was suitable for social economy and culture system at that time as to the industrial pattern, discipline pattern and education pattern. Due to the accumulation of the $1980 \mathrm{~s}$ and $1990 \mathrm{~s}$, the new cultural and economic prosperity after the late 1990s has further confirmed the acceleration of the reform on traditional arts and crafts in the 1980s and 1990s.

\section{REFERENCES}

[1] [Japan] Liu Zongyue. Craft Culture. Translator Xu Yiyi [M]. Guilin: Guangxi Normal University Press, 2006.
[2] Xi Xie. Formation and Enhancement of Chinese Modern Art Design Consciousness - View "Art and Design" from Three Concepts of "Pattern", "Arts and Crafts" and "Art Design" [J]. Nanjing: Editorial Department of Journal of Nanjing Arts Institute. (2004 03): 87-88.

[3] Wang Wenzhang. Review and Prospect of the Cultural Industry during the 30 Years of Reform and Opening Up Policy [A]. Zhang Xiaoming, $\mathrm{Hu}$ Huilin \& Zhang Jiangang. 2009 Development Report of Chinese Culture Industry [M]. Beijing: Social Sciences Academic Press, 2009.

[4] Wang Lidan. Record of Interview of Chinese Traditional Arts and Crafts System - Review of Cultural Reform and Development of the Past 60 Years Since the PRC's Foundation. Hundred Schools in Arts [J], 2009 (02): 144-148. 